\title{
Investigating soil water retention characteristics at high suctions using relative humidity control
}

\author{
Vasileios Mantikos ${ }^{1, a}$, Steven Ackerley ${ }^{1}$, Andrew Kirkham ${ }^{1}$, Aikaterini Tsiampousi ${ }^{1}$, David M.G. Taborda ${ }^{1}$ and Jamie \\ Standing ${ }^{1}$ \\ ${ }^{1}$ Department of Civil and Environmental Engineering, Imperial College, London, United Kingdom
}

\begin{abstract}
A technique for controlling relative humidity (RH) is presented, which involves supplying a sealed chamber with a continuous flow of air at a computer-regulated RH. The desired value of RH is achieved by mixing dry and wet air at appropriate volumes and is measured for servo-control at three locations in the chamber with capacitive RH sensors and checked with a sensitive VAISALA sensor. The setup is capable of controlling RH steadily and continuously with a deviation of less than $0.2 \% \mathrm{RH}$. The technique was adopted to determine wetting soil-water retention curves (SWRC) of statically compacted London Clay, under both free-swelling and constant volume conditions. The RH within the chamber was increased in a step-wise fashion, with each step maintained until vapour equilibrium between the chamber atmosphere and the soil samples was established. Independent filter paper measurements further validate the method, while the obtained retention curves complement those available in the literature for lower ranges of suction.
\end{abstract}

\section{Introduction}

The soil-water retention curve (SWRC) relates suction to water content or degree of saturation and has long been shown to be highly non-linear and hysteretic. Traditionally, measurement of the SWRC in the laboratory in the laboratory involves exposing soil samples to a certain suction and recording their mass through a sequence of suction levels. The results are commonly presented by plotting the calculated degree of saturation or volumetric water content against suction in a semi-logarithmic plot.

The retention capacity of soils is specific volume dependent [1, 2]. Ideally volume should be either controlled or measured while wetting/drying, especially for expansive clays, where the volume changes may be significant. Alternatively, the SWRC can be presented in terms of gravimetric water content, although it does not provide any information on volumetric change effects.

To obtain the SWRC, knowledge of the current value of suction is necessary. Suction can be measured in a direct or indirect manner. Measurement techniques suitable to determine suction include dew-point hygrometer, transistor/thermistor psychrometer, thermocouple psychrometer, filter paper method, tensiometers, electrical/thermal conductivity sensors, resistance/ capacitive sensors [3, 4]. Many methods for measuring total suction actually acquire a value for relative humidity which is then converted to suction using Kelvin's thermodynamic law.
The basic concepts behind suction control can be classified in three general types. A common method for controlling suction is the axis-translation technique, where the air and water pressures in the system are increased by the same amount keeping matrix suction constant, until water pressure is positive and can be measured conventionally $[5,6]$. Another way to control suction is the osmotic technique, where the sample is in contact with a salt solution (e.g. PEG, polyethylene glycol) through a semi-permeable membrane, achieving a value of matrix suction of up to $12 \mathrm{MPa}[7,8]$. Finally, using Kelvin's law in reverse, it is possible to control the total suction in a soil specimen by controlling the relative humidity of its environment [9]. This is usually achieved by means of thermodynamic equilibrium between the air in a closed chamber and an unsaturated acid or a saturated salt solution. Another method for RH control described by Lu and Likos [4] is the divided-flow method which relies on the proportionate mixing of saturated and dry air. Variations of the latter method have also been adopted in sorption balances and gravimetric analysers in Material sciences and the food industry.

This paper focuses on the development of a suction control equipment in the geotechnical laboratory of Imperial College London. Suction values in the range of $10 \mathrm{MPa}$ to $300 \mathrm{MPa}$ are achieved inside sealed chambers through servo-control of relative humidity (RH). A particular application of the technique relates to the determination of SWRCs of expansive clays over high suction ranges, e.g. compacted bentonite used as buffer in nuclear waste disposal. The divided-flow method and the

\footnotetext{
${ }^{\mathrm{a}}$ Corresponding author: vasileios.mantikos12@imperial.ac.uk
} 
capacitive sensors were selected to control and measure RH respectively. A brief description of the development of the equipment is presented in the current paper, followed by the results of its application for two common soils. A comparison with the filter paper method is also carried out.

\section{Development of equipment}

\subsection{Description}

Pictures of the components and a schematic depiction of the arrangement are presented in Figures 1 and 2 respectively. The equipment consists of a manostat, two water excluders, a water filled saturation chamber, a perforated steel tube (bubbler), plastic tubes, two valves, a sealed chamber, a perforated tray, a fan, a rod with three attached temperature and $\mathrm{RH}$ capacitive sensors, a constant volume cell, an auxiliary brass cell for compaction, a micro-computer control system, a data logger and a computer.

\subsection{Air-flow system}

The divided-flow principle is employed in order to apply suction in samples in the range of $10 \mathrm{MPa}$ to $300 \mathrm{MPa}$. For reasons of convenience the circulating gas is compressed air from the main laboratory supply at a $\mathrm{RH}$ of approximately $5 \%$. The air supply is reduced to a safe pressure with a manostat. The air is routed through a water exclusion chamber, where any condensed moisture is collected at its base. The flow is then divided into two streams. One is injected through a perforated metal tube through a water bath to be saturated. The "wet" stream is routed through a second water excluder, before both "dry" and "wet" streams enter the sealed chambers at flows individually controlled by two valves, at a computer-controlled wet/dry ratio. Temperature and relative humidity in the chambers are recorded using capacitive probes connected to data loggers, giving feedback to the computer program controlling the valves. The chamber is sealed, but for a small diameter vent to prevent potential pressure build up.
Having an open system instead of recycling the air and circulating it back into the system improved control and reduced the response time of the system. Having a continuous flow of controlled-humidity air provided better control rather than injecting dry or wet air only for corrections.

The total air-flow into the first excluder is maintained constant using a manual manostat. The manostat reduces the pressure of the supplied air to $15-20 \mathrm{kPa}$. Higher air pressure introduced in the system might cause failure of the seals at the connections of various components, with the valves being the most sensitive parts. If, on the other hand, the pressure is too low, humidity flow might reverse, making the system sensitive to changes in the laboratory environment. Maintenance and cleaning of all tubes and components should be performed regularly to avoid blocking and clogging of the flow path.

To avoid condensation, water excluders were introduced in the system, the length of tubes was reduced, sagging of the tubing was avoided and metal tube connectors were replaced with plastic ones.

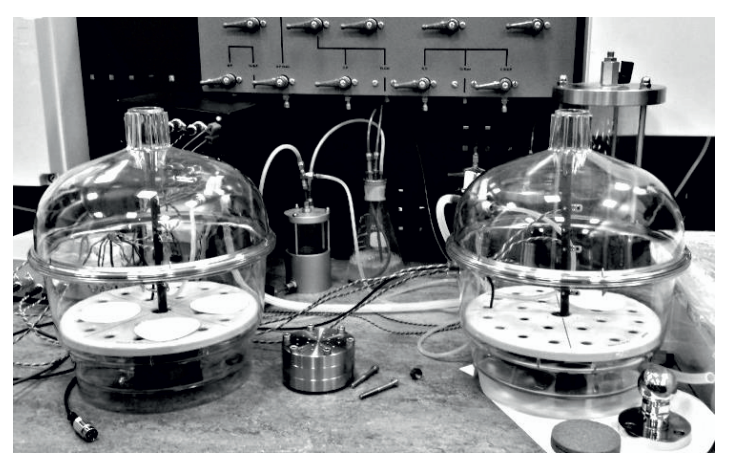

Figure 1. Two chambers in operation.

\subsection{Constant volume cell}

A perforated steel cell was developed to keep the volume constant during wetting, while allowing moisture to travel through the sample. The cell concept is similar to those used in CIEMAT [10]. The cell was modified at Imperial College so that the sample is placed in a ring and confined at the top and bottom with perforated discs fitted with porous stones (Figure 3).

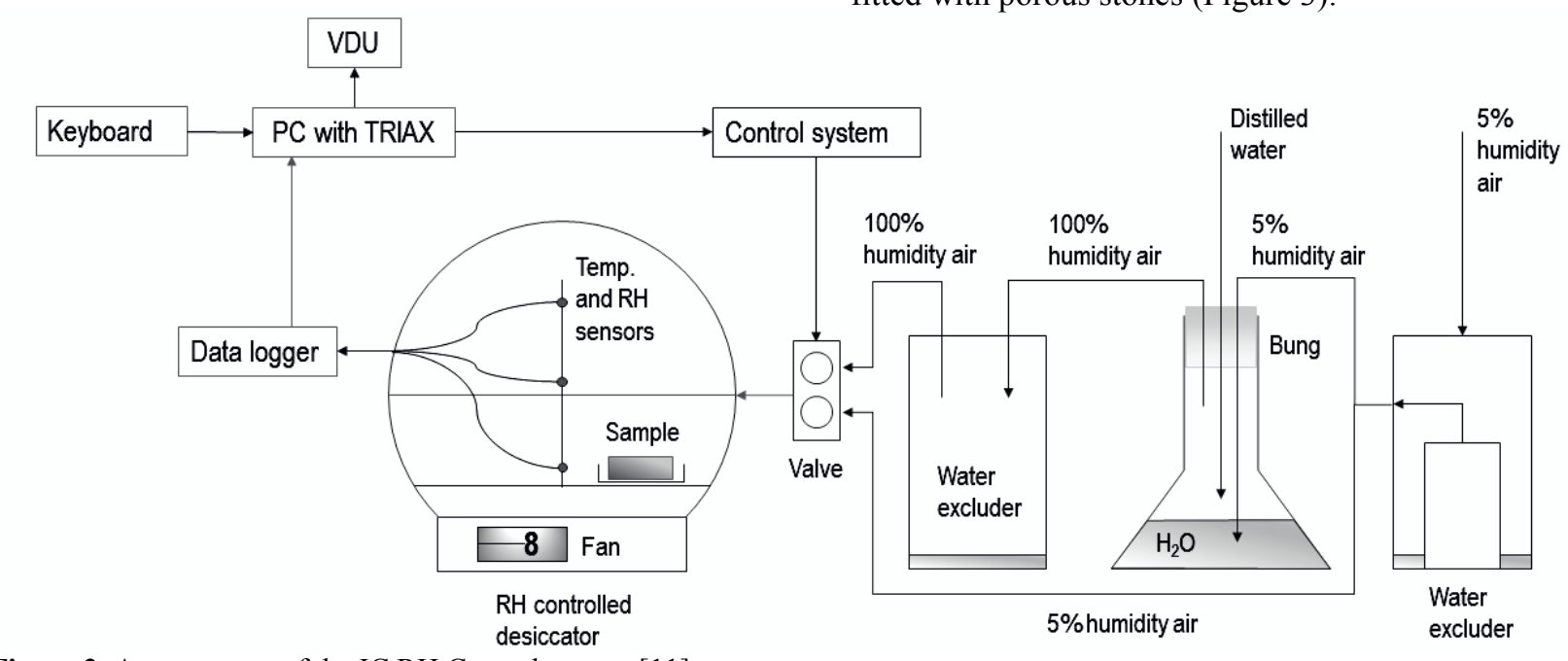

Figure 2. Arrangement of the IC RH Control system [11]. 
Confining rings of different heights can be employed according to the needs of the experiment. The initial ring was manufactured at a $15 \mathrm{~mm}$ height. Six screws hold the discs and ring together, but also raise the base of the cell above the perforated tray thus allowing circulation of air. The steel used for the construction of the cell was the corrosion resistant AMINOX-AS-1®, to counter the corrosive properties that some soils may exhibit, e.g. bentonite. The choice of $85 \mathrm{~mm}$ diameter cell allows simultaneous fitting of four samples in the chamber. Considering that the available scale has a resolution of $0.01 \mathrm{~g}$ and a capacity of $3 \mathrm{~kg}$, the cell provides a sample large enough to obtain a resolution of $0.015 \%$ in water content measurements assuming a minimum $1.3 \mathrm{~kg} / \mathrm{cm}^{3}$ dry density, while the total mass of soil and cell does not exceed $2.5 \mathrm{~kg}$. Considering the use of the cell for expansive soils, it was found that $10 \mathrm{~mm}$ thick walls would deform less than $0.05 \mathrm{~mm}$ under $15 \mathrm{MPa}$ of swelling pressure. This leads to the cell design shown in Figure 3.

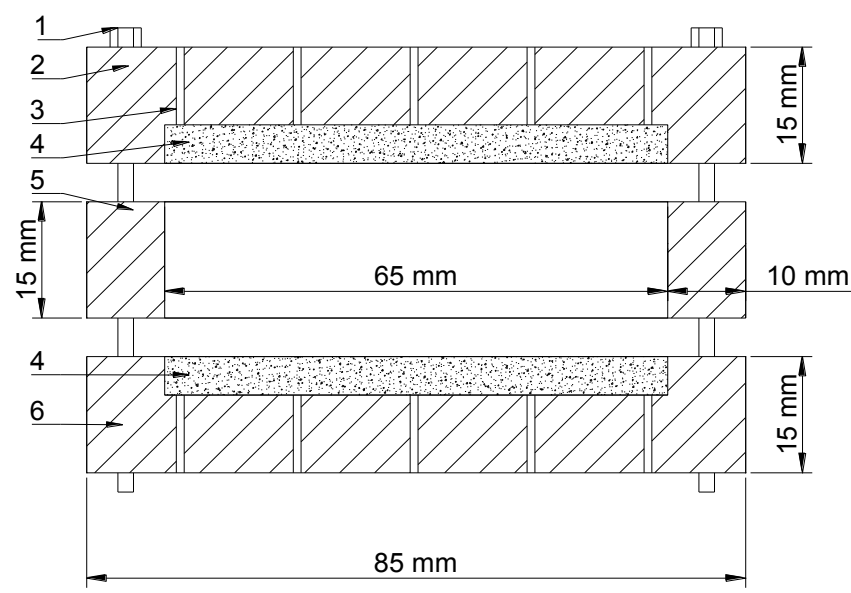

Figure 3. Dimensions of the IC constant volume cell. 1. Long screws, 2. Top perforated disc, 3. Perforations, 4. Coarse porous stones, 5 . Confining ring, 6 . Base perforated disc.

\section{Validation tests}

\subsection{Control operation}

A series of increasing/decreasing humidity cycles has been performed to check the response of the system. The parameters examined are the standard deviation of $\mathrm{RH}$ once at equilibrium, the system's stability over changes in laboratory humidity and temperature, and stability against loss of services (e.g. power or air supply and computer communication errors).

The humidity in the chamber is compared to the humidity in the laboratory in Figure 4. It is observed that variations in the environment of the laboratory do not affect the RH conditions in the chamber. The spikes in the chamber measurements represent occasions of opening the lid of the chamber. During a 5-day period with no computer control after a computer communication system crash, the $\mathrm{RH}$ in the chamber remained unchanged, suggesting that the valves continued regulating RH successfully at the previously set target value.

\subsection{Capacitive sensors}

$\mathrm{RH}$ and temperature are recorded using common capacitive sensors of $1 \% \mathrm{RH}$ accuracy and $0.001 \% \mathrm{RH}$ resolution. The sensors are calibrated against a precalibrated high-accuracy VAISALA sensor. To reduce uncertainty three sensors were used simultaneously in the chambers. The fluctuation of a single sensor was limited to $0.2 \% \mathrm{RH}$. The deviation of $\mathrm{RH}$ change among the sensors was less than $0.1 \% \mathrm{RH}$, showing a similar trend for each sensor with $0.1 \%$ deviation (Figure 5).

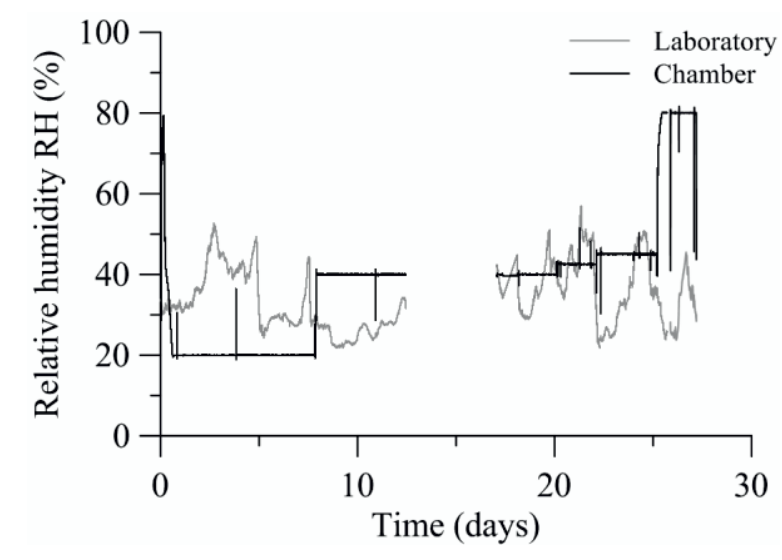

Figure 4. Comparison between RH of laboratory and environmental chamber.
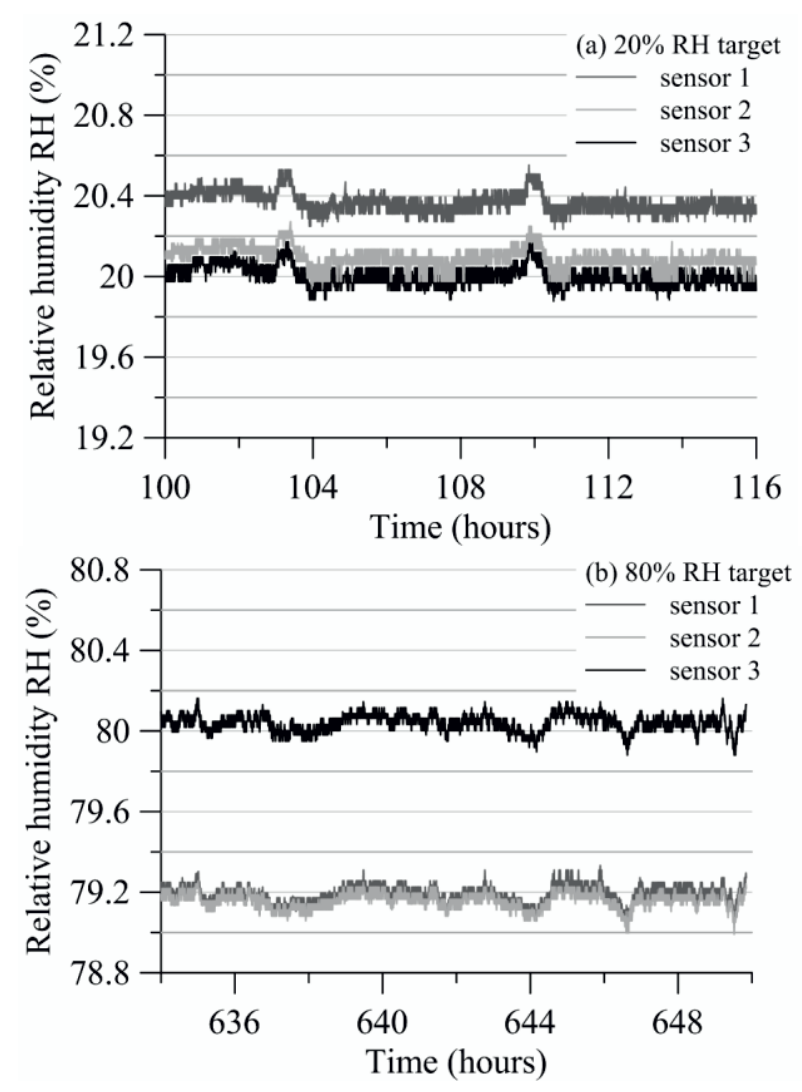

Figure 5. RH readings inside chamber at a target value of (a) $20 \% \mathrm{RH}$ and (b) $80 \% \mathrm{RH}$. 
In Figure 5 the $\mathrm{RH}$ readings of the three sensors in a chamber are presented, with sensor 1 being the highest. Sensor 3 was positioned at the level of the perforated tray, at the same level that the soil samples would be, and therefore it was chosen as the control sensor for feedback to the computer program. While sensor 3 kept reading a value around the target $\mathrm{RH}$ (black line), the other two sensors drifted either towards a higher (Figure 5a) or a lower (Figure 5b) value of RH, for low and high target $\mathrm{RH}$ respectively.

\subsection{Constant volume cell}

A soil sample was compacted and placed in the constant volume cell to investigate its effectiveness in terms of hydration. The soil used was oven-dried, pulverised London Clay, compacted at $0.4 \%$ water content under a 1.8 MPa compaction load.

The cell was placed in the $\mathrm{RH}$ chamber to equilibrate at $80 \%$ RH. The limited free surface through which the cell can exchange water with the humid environment of the chamber, the sample being oven-dried and the large change in suction levels are factors that were expected to delay the hydration process. After 32 days the sample was still absorbing moisture, indicating that equilibrium had not yet been achieved.

An estimation of the required time for equilibrium was thought to be 40 days. This value was derived by fitting a straight line in the semi-logarithmic plot of rate of change in mass with time shown in Figure 6. It should be noted that the above time value represents the maximum expected time for equilibrium to be reached for the examined soil, as the suction step applied was the maximum allowed by the equipment.

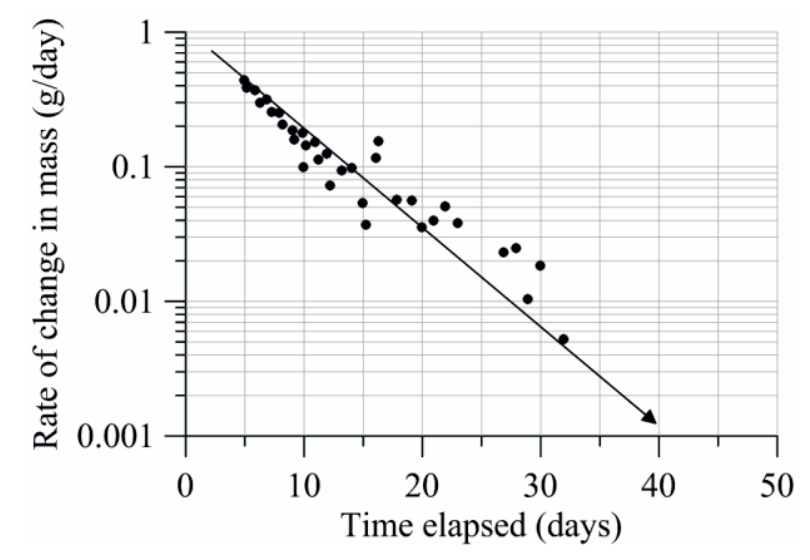

Figure 6. Change of mass of soil sample inside cell for a change in RH from $0 \%$ to $80 \%$.

\section{Experimental results}

\subsection{Black cotton soil}

A soil sample of black cotton clay, previously studied by Al Haj [12], was tested in the RH chamber. The soil sample was loosely placed in the chamber on a tray at an initial water content of $58.4 \%$. The initial $\mathrm{RH}$ target value was set at $20 \%$, gradually increasing up to $80 \%$. The range of applied $\mathrm{RH}$ corresponds to an initial suction of $200 \mathrm{MPa}$ (i.e. $20 \% \mathrm{RH}$ ), followed by wetting steps up to a suction of $30 \mathrm{MPa}$ (i.e. $80 \% \mathrm{RH}$ ).

The mass of the sample was frequently measured using a $0.01 \mathrm{~g}$ resolution scale. This involved removing samples from the chamber, sealing the trays with a top cap, taking the mass measurement quickly and carefully and placing the sample back into the chamber. Equilibrium was assumed to have been achieved when the change in mass was less than $0.01 \mathrm{~g}$ for 12 hours. The derived gravimetric water content is plotted against total suction in Figure 7. The SWRC derived by Al Haj [12] using the filter paper method, with the Chandler \& Guiterez [13] calibration for Whatman No.42 filter papers for suction values up to $30 \mathrm{MPa}$, is also included for comparison. The wetting path measured with the new system is in good agreement with Al Haj's wetting curve.

\subsection{London Clay}

Subsequently, a series of tests was performed using London Clay, similar to the one tested by Monroy [14]. The initial material was air-dried, ground into powder and sieved before being stored in a large container in the storage room where RH was estimated to be about $63 \%$. The Atterberg limits were measured using the cone penetrometer and the standard rolling method, as described in BS 1377-2:1990 [15]. The particular London Clay was found to be of very high plasticity $(\mathrm{PL}=0.28$, $\mathrm{PI}=0.52$ ). According to particle density tests using the glass jar method, the specific gravity, $G_{s}$, has a value of 2.75 [11].

Eight $65 \mathrm{~mm}$-diameter samples were compacted at 1.8 $\mathrm{MPa}$, at an initial water content of $7.3 \%$. Four of the samples were subjected to wetting, with $\mathrm{RH}$ ranging from $60 \%$ to $80 \%$ ( $70 \mathrm{MPa}$ to $30 \mathrm{MPa}$ of suction) while the other four were oven dried prior to being subjected to a wetting path from $10 \%$ to $70 \% \mathrm{RH}(310 \mathrm{MPa}$ to $50 \mathrm{MPa}$ of suction). Two additional samples of pulverised London Clay were loosely placed on a tray and were subjected to a range of $10 \%$ to $85 \% \mathrm{RH}(310 \mathrm{MPa}$ to $20 \mathrm{MPa}$ of suction), with one of them being initially oven-dried. Because of their uneven shape, the volume of these samples, and therefore their void ratio values, could not be calculated.

The SWRCs are plotted in Figure 8 in terms of gravimetric water content. As expected, the curves for the oven-dried samples $(0 \% \mathrm{w} / \mathrm{c})$ plot at a lower water content than the air-dried samples $(6.1 \%$ \& $7.3 \% \mathrm{w} / \mathrm{c})$. Also, compacted samples plot above the pulverised loosely placed samples, possibly due to different void ratios obtained during preparation.

Also plotted for comparison are SWRCs for a reconstituted London Clay by Dineen [7], consolidated under $200 \mathrm{kPa}$ pressure and subjected to a cycle of drying (grey curve in Figure 8) and wetting (black curve in Figure 8). Additionally, Mavroulidou et al. [16] obtained two drying curves for an untreated pulverised London Clay. The samples were compacted at a dry density of $1.43 \mathrm{~g} / \mathrm{cm}^{3}$ at $27 \%$ (dry of optimum) and at $32 \%$ (wet of optimum) water contents. Both Dineen and Mavroulidou 
et al. used the filter paper method with the Chandler \& Guiterez [13] calibration for Whatman No.42 filter papers.

The curves derived by Dineen for the reconstituted London Clay plot below the ones for the compacted samples obtained by Mavroulidou et al., perhaps due to differences in preparation. The two drying paths from Mavroulidou et al. plot close to the ones obtained in the present study, despite the differences in the compaction method and the origin of the soil.

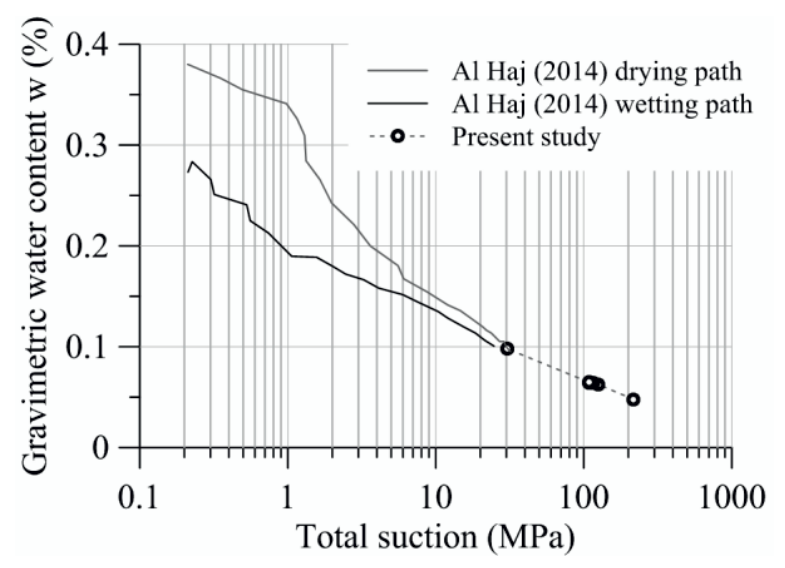

Figure 7. Soil Water Retention Curves for black cotton clay.

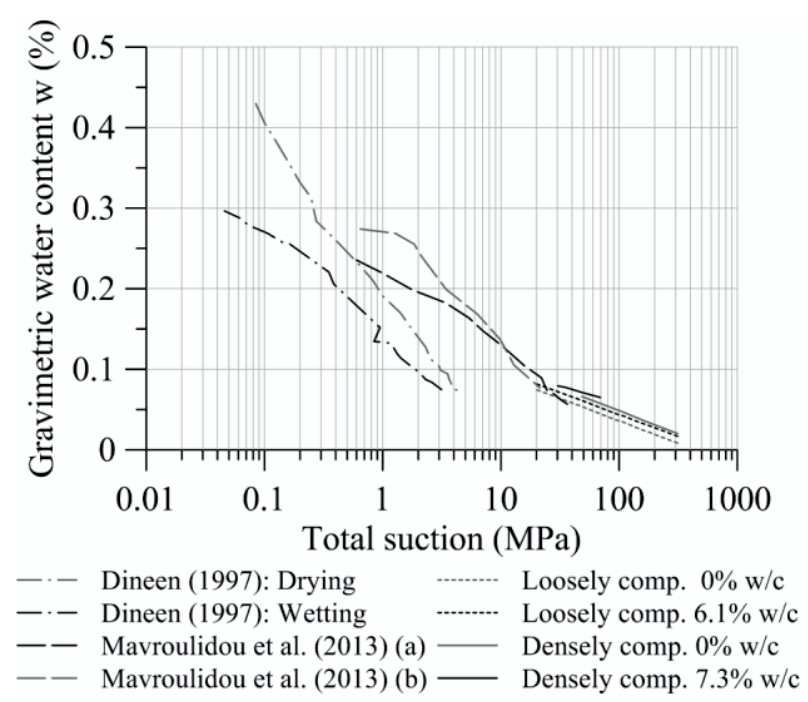

Figure 8. Soil Water Retention Curves for London Clay.

\subsection{Comparison with filter paper measurements}

This series allowed calibration of the $\mathrm{RH}-\mathrm{w} / \mathrm{c}$ curves for the particular filter papers used (Whatman No.42) at suctions higher than $30 \mathrm{MPa}(\sim 80 \% \mathrm{RH})$, which was then used to compare the two techniques. Therefore, two series of tests involving filter papers were conducted. In the first series, the subject of the tests was the filter papers themselves, while in the second series filter papers were used for indirect measurement of suction within soil samples.

More specifically, in series A, the filter papers were directly placed in a $\mathrm{RH}$ chamber and were exposed to different levels of RH. Three filter papers were placed in chamber A (fp_A2, fp_A3 \& fp_A4) and subjected to consecutive $\mathrm{RH}$ values from $10 \%$ to $85 \%$ (310 $\mathrm{MPa}$ to 20 $\mathrm{MPa}$ of suction), while an additional filter paper was placed simultaneously in chamber B (fp_B2) and was subjected in a single step to a change in $\mathrm{RH}$ from $10 \%$ to $85 \%$ to examine any equilibration time effects. These are compared to the following calibration curves from the literature in Figure 9:

Chandler and Gutierrez [13] for up to $30 \mathrm{MPa}$,

$$
w=(4.842-\log \psi) / 0.0622
$$

Fawcett and Collis-George [17]:

$$
w=(5.327-\log \psi) / 0.0779
$$

and Likos and $\mathrm{Lu}[18]$ :

$$
w=(5.5-\log \psi) / 0.13
$$

Of the three calibration curves, the one proposed by Likos and Lu gives a better fit to the experimental points of series A, predicting drier filter papers by approximately $1 \%$ water content. An additional curve was custom fitted to the results of series A (Figure 9), as an upper boundary to the obtained experimental data:

$$
w=(5.7-\log \psi) / 0.13
$$

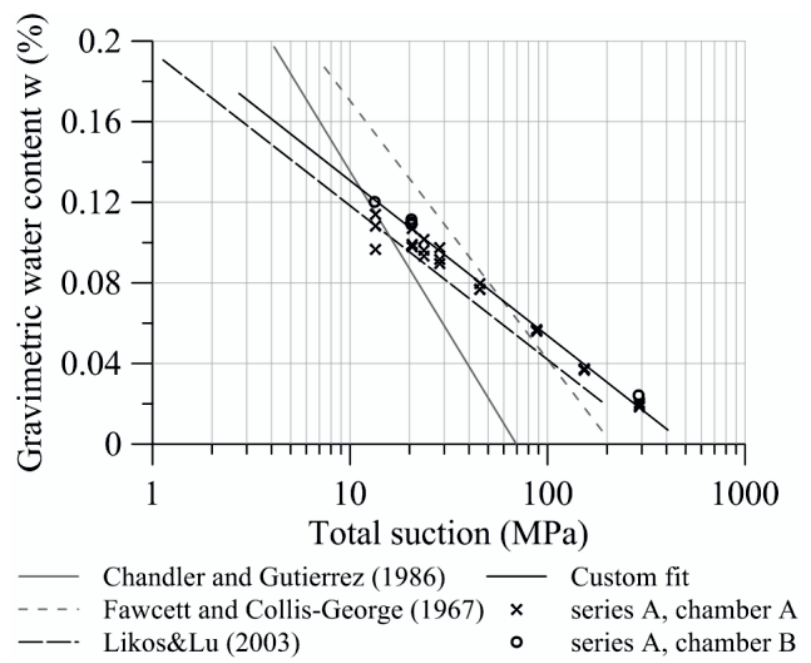

Figure 9. Filter paper calibration data and comparison with calibration curves found in the literature.

In series $\mathrm{B}$ the filter paper technique was used to measure the suction of soil samples (London Clay, 2MPa, $7.3 \% \mathrm{w} / \mathrm{c}$ ) treated in the RH chamber at different levels of RH, namely $70 \% \mathrm{RH}, 75 \% \mathrm{RH}, 77.5 \% \mathrm{RH}$ and $80 \%$ RH. One sample was prepared at each RH level. The suction applied to the samples is plotted against their gravimetric water content (symbol $\mathbf{x}$ in Figure 10).

The procedure recommended by Ridley et al. [3] and described in Kokkinou [19] was followed after the samples were removed from the chamber to determine the water content of the filter papers. The predictions of the aforementioned calibration curves (Eq. 1-4) for each sample are included in Figure 10.

The calibration of Likos and Lu (Eq. 3) compares relatively well to the suction estimated from the thermodynamic law for the equilibrium $\mathrm{RH}$ at the time of 
removal of the soil samples from the chamber. Eq. 4, on the other hand, overestimates significantly the suction measured in the sample, in this range (50MPa to $30 \mathrm{MPa})$.

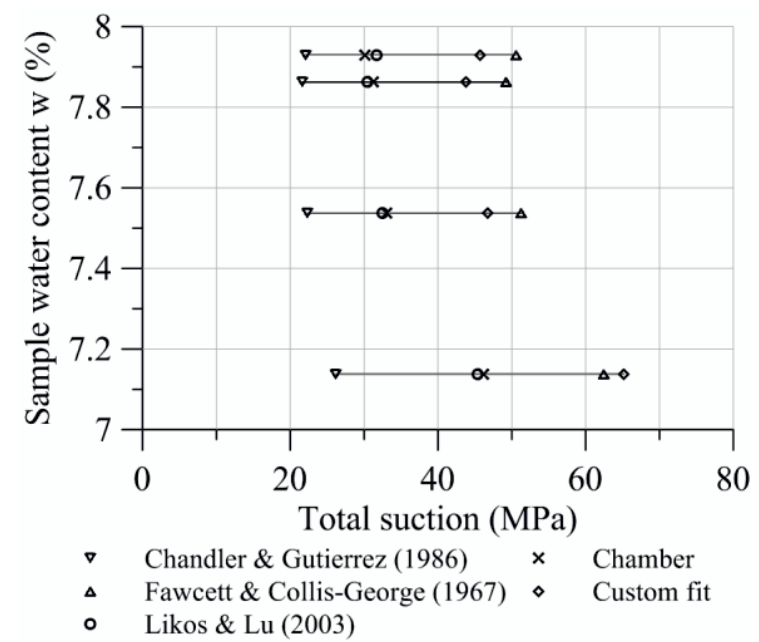

Figure 10. Comparison of suction prediction for series B using different filter paper calibration curves.

\section{Summary}

A method of controlling $\mathrm{RH}$ in chambers is presented and has been shown to provide an accurate control $(0.2 \% \mathrm{RH}$ standard deviation) of relative humidity in an environmental chamber for a range of $10 \% \mathrm{RH}$ to $85 \%$ $\mathrm{RH}$. The control is fully automatic, but the recording of mass is still manual. The $\mathrm{RH}$ conditions can be successfully held constant for long periods without any effect from the laboratory humidity.

The SWRCs derived for two soils using this method show good agreement with data presented in the literature for similar soils. An upper boundary calibration for Whatman No.52 filter paper for suction values larger than $30 \mathrm{MPa}$ is suggested, but the Likos \& Lu calibration curve fits better to the measurements of sample suction.

\section{Acknowledgements}

The first author is supported by a Skempton scholarship and the project is partly funded by Radioactive Waste Management ltd (RWM). The method has been developed thanks to the engineering skills of Duncan Parker.

\section{References}

1. A. Tsiampousi, L. Zdravkovic, and D.M. Potts, $A$ three-dimensional hysteretic soil-water retention curve. Geotechnique, (2013). 63(2): p. 155.

2. D. Gallipoli, S.J. Wheeler, and M. Karstunen, Modelling the variation of degree of saturation in a deformable unsaturated soil. Geotechnique, (2003). 53(1): p. 105.
3. A.M. Ridley, K. Dineen, J.B. Burland, and P.R. Vaughan Soil matrix suction: some examples of its measurement and application in geotechnical engineering. Géotechnique, (2003). 53, 241-253.

4. N. Lu and W.J. Likos, Unsaturated Soil Mechanics. (2004), Hoboken, New Jersey: John Wiley \& Sons.

5. J.W. Hilf, An investigation of Pore-Water pressure in compacted cohesive soils. (1956), Thesis, University of Colorado.

6. P. Delage, M.D. Howat, and Y.J. Cui, The relationship between suction and swelling properties in a heavily compacted unsaturated clay. Eng.Geol., (1998). 50(1-2): p. 31.

7. K. Dineen, The influence of soil suction on compressibility and swelling. (1997), PH.D Thesis, Imperial College.

8. R. Monroy, A. Ridley, K. Dineen, and L. Zdravkovic, The suitability of the osmotic technique for the long-term testing of partly saturated soils. Geotechnical Testing Journal, (2007). 30(3): p. 220.

9. P. Delage, E. Romero, and A. Tarantino, Recent developments in the techniques of controlling and measuring suction in unsaturated soils. Unsaturated Soils: Advances in Geo-Engineering, (2008): p. 3352.

10. M.V. Villar. Reseacrcher. (Personal communication, September 2013)

11. A. Kirkham, Novel experimental technique for the measurement of hydraulic properties of geomaterials. (2015), MEng Dissertation, Imperial College London.

12. K. Al Haj, Mechanical response of two plastic clay soils from Sudan. (2014), Ph.D Thesis, Imperial College London.

13. R.J. Chandler and C.I. Gutierrez, Filter-paper method of suction measurement. Geotechnique, (1986). 36(2): p. 265-268.

14. R. Monroy, The influence of load and suction changes on the volumetric behaviour of compacted London clay. (2006), Ph.D Thesis, Faculty of Engineering Imperial College London.

15. British Standards Institute, BS 1377-2:1990 Methods of test for soils for civil engineering purposes. Classification tests. (1990), British Standards Institute: London.

16. M. Mavroulidou, Z. Xiwei, M.J. Gunn, and Z. Cabarkapa, Water Retention and Compressibility of a Lime-Treated, High Plasticity Clay. Geotech.Geol.Eng., (2013). 31(4): p. 1171-85.

17. R. Fawcett and N. Collis-George, A filter-paper method for determining the moisture characteristics of soil. Australian Journal of Experimental Agriculture, (1967). 7(25): p. 162-167.

18. W.J. Likos and N. Lu, Automated humidity system for measuring total suction characteristics of clay. Geotechnical Testing Journal, (2003). 26(2): p. 179190.

19. A. Kokkinou, Investigation of soil water retention curves of compacted clays. (2014), MSc Dissertation, Imperial College London. 